Nabil B. AMRANI ${ }^{1,2}$, Laurent SAINTIS ${ }^{1}$, Driss SARSRI ${ }^{2}$, Mihaela BARREAU ${ }^{1}$

${ }^{1}$ LARIS, Engineering School ISTIA, University of Angers, France

${ }^{2}$ LTI, National School of Applied Sciences, ENSA-Tangier, UAE, Morocco

\title{
DYNAMIC BAYESIAN NETWORK FOR RELIABILITY OF MECHATRONIC SYSTEM WITH TAKING ACCOUNT THE MULTI-DOMAIN INTERACTION
}

\begin{abstract}
This article presents a methodology for reliability prediction during the design phase of mechatronic system considered as an interactive dynamic system. The difficulty in modeling reliability of a mechatronic system is mainly due to failures related to the interaction between the different domains called Multi-domain interaction. Therefore in this paper, after a presentation of the state of the art of mechatronic systems reliability estimation methods, we propose a original approach by representing multi domain interactions by influential factors in the dysfunctional modeled by Dynamic Bayesian Networks. A case study demonstrates the interest of the proposed approach.
\end{abstract}

Keywords: Predictive Reliability, Quantitative modeling, Dynamic Hybrid System, Mechatronics, Multi-domain Interactions, Dynamic Bayesian Network

\section{Introduction and context}

Nowadays, the increasing complexity of mechatronic systems requires an intensive collaboration between engineers of different fields, such as mechanic, electronic, automatic and software, in a design team. As definition [5], mechatronics is the synergistic combination of mechanical engineering with electronics and intelligent computer control in the design and manufacturing of industrial products and processes. The study of mechatronic reliability is now a young science, a central issue is this reliability model cannot be considered for one technical domain, because these domains complete and influence each other. Thus, the complexity of mechatronic systems is a real scientific challenge for industries, and an interesting research field, in order to make safer products and more reliable systems, and allows taking optimal orientations in the field of design. 
As we notice in bibliography $[3,8,10,14,18]$, mechatronic system are described by different aspects such as dynamic, hybrid, interactive, and reconfigurable. A dynamic system describes the evolution of a state over time. Hybrid systems are systems involving explicitly and simultaneously continuous phenomena and discrete events [14]. A reconfiguration system is a discrete control system designed to react when failures of the system's components occur; it is a system capable of changing its internal structure in order to ensure the function. Furthermore, dynamic reconfiguration improves the stability of systems [8]. The interactive nature of a system is defined by the existence of physical dysfunctional interactions between the components of the system, so how should we evaluate this model of predicted reliability into account these aspects, and what are the relevant tools allowing a better modeling?

This paper focuses on predicting the reliability of mechatronic systems with taking into account of the multi domain interactions (Interactive aspect). We present relatively detailed presentation of some studies which are very close to this issue, then we propose our contribution for multi-domain interactions, during the predicted reliability assessment, based on the Dynamic Bayesian Networks. Finally, to illustrate the interest of the proposed approach, our methodology was tested on an industrial application Smart Actuator.

\section{State of art}

The predicted reliability studies focused on taking into account these characteristics (dynamic, hybrid, interactive, and reconfigurable), as well as the impreciseness of reliability models in order to design a safe mechatronic system. For that reason, a method proposed by $\mathrm{S}$. Khalfaoui $[1,10]$ to take into account the dynamic and hybrid aspects for the modeling of mechatronic systems, he proposes to extract all possible scenarios leading to the undesired state using Petri Net. Also, Ziegler [21] proposed a global approach for applications in automotive systems, by taking into account of the different architectures in the early phases. Moncelet [15] considered mechatronic system as hybrid systems and he used colored Petri nets to model a pressure tank system. Shoeing [17] defined a methodology for the design of control subsystem in order to integrate the conception activities by using Petri Nets and Markov graphs.

A. Mihalache [14] proposed an approach based on qualitative modeling, divided in functional and dysfunctional analysis, followed by a quantitative modeling using deterministic and stochastic Petri nets, and on the operative field data (REX). This approach was applied to a braking system ABS. A. Demri [8] followed the 
same approach based on qualitative and quantitative modeling using Petri Net, using the method PHI-2 for modeling the mechanical parts. More recently, the tool Information Flow Approach was used to model the reliability of Smart Sensor [4]. All these studies are important for the scientific community, but they do not take into account others important mechatronic aspects like reconfigurable and interactive aspects, the latter being still ambiguous. It should be noticed that few studies focus on the interactive aspect and none on the multi-domain interactions in reliability prediction, except for the methodology proposed by G. Habchi [9]. He proposed to implement the classical methodology: qualitative and quantitative modeling using Petri nets, and to use organic analysis for multi-domain interactions. This is an analysis of the organ/organ interactions, resulting from an organic architecture showing the location of the different components and their links.

As definitions in bibliography, we find that A. Demri [8] presents interaction as the relation between constituents, which is most often expressed in complex systems by a relation of influence or exchange that relates to material, energy and/or information flows. Also it is necessary to distinguish between two types of interactions [7]. Firstly, there are the interactions between a physical process (such as pressurization, heating or heat exchange) and its control. Secondly, there are the interactions between software and hardware components, the presence of communication networks, multitasking treatments, or multiplexing within the control. Finally, Belhadaoui [4] defined the hardware/software interaction as the presence of a software layer executed on the hardware architecture.

\section{Proposed methodology}

To our knowledge, there is no methodology to evaluate the reliability of mechatronic systems taking into account the existence of multi-domain interactions. Here, a global approach for the predictive evaluation of mechatronic systems in the design phase is described in the following figure 1 . 


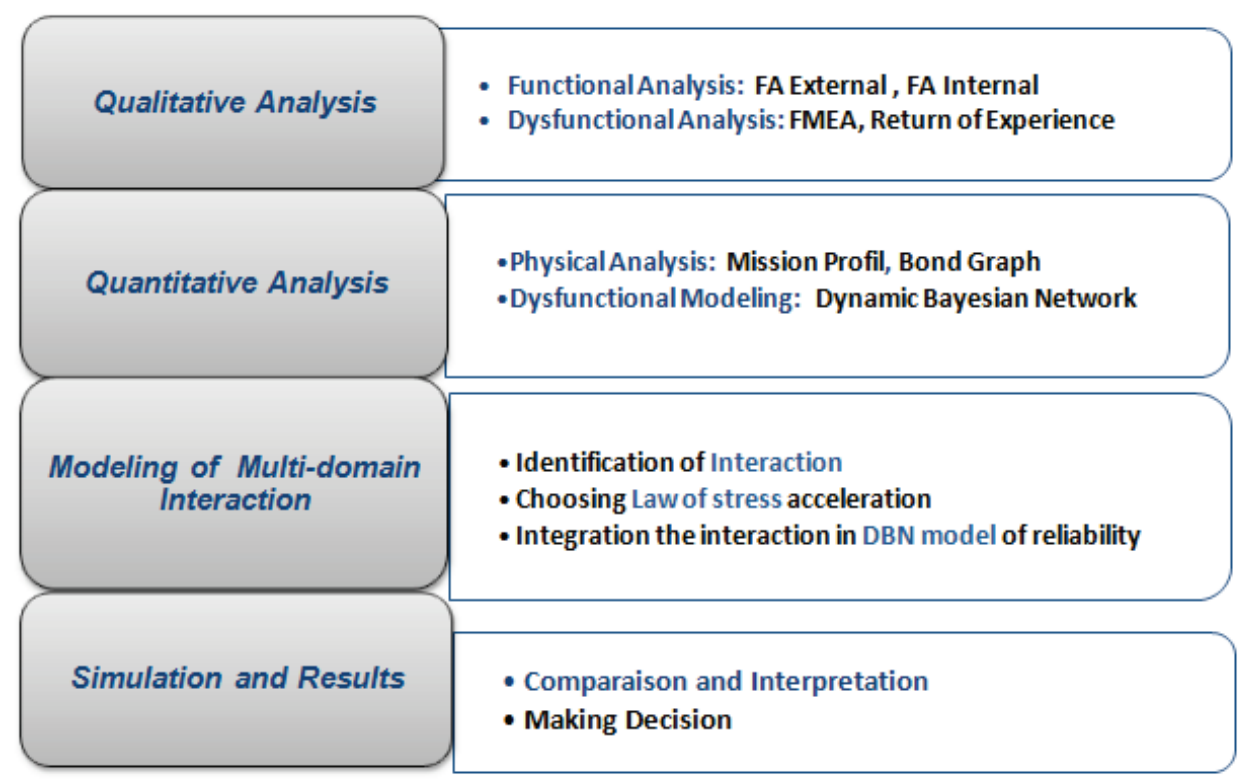

Fig. 1. Proposed approach for predictive reliability of mechatronic systems

\subsection{Qualitative modeling of system}

The qualitative analysis is based in two analyses: functional and dysfunctional. The functional one allows a tree-shaped decomposition of the system by the methods of Functional Analysis System Technique (F.A.S.T), and Structured Analysis and Design Technique (S.A.D.T). Dysfunctional analysis is established by the Failure Modes and Effect Analyses (FMEA), the basic process consists of compiling lists of possible component failure modes, gathered from descriptions of each part of the system, and then trying to infer the effects of those failures on the rest of the system.

\subsection{Quantitative modeling of system}

To compute the predicted reliability, there are several existing methods and models [15], such as Fault Tree Analysis (FTA), Reliability Block Diagram (RBD), Markov chains (MC), or minimal cut [16], Stochastic Petri nets [2], Bayesian Networks $(\mathrm{BN})$ and neural networks. Among these tools, FTA, RBD and all static methods are not applicable to mechatronic systems, because these tools do not take into account the dynamic aspect [17]. We have chosen to use Bayesian networks since they are suited for modeling the reliability of complex system [6], they are an 
unified framework that represents the relationships between the random and discrete variables $[6,12]$. BN also allow taking into account the probabilities of a priori failure of the components [12].

Therefore $\mathrm{BN}$ are a well-suited tool for reliability analysis of complex systems, their application is relatively recent and efficient and presented in many works. Our choice of Dynamic Bayesian Networks (DBN) as a tool for reliability modeling is based on the following criteria: Treatment of Continuous variables [11], Hierarchical Modeling, Representation of dependencies between failures [12], estimation of uncertainties [6]. Bayesian networks have an advantage in building dependency relationships. The model not necessitates specifying the failure distribution for each component as example [12].

\subsubsection{Dynamic Bayesian Networks}

A Bayesian network is a graphical structure that allows representing an uncertain domain. The nodes in a Bayesian network represent a set of random variables $\mathrm{xi}$ from the domain. A set of directed arcs (or links) connects pairs of nodes $(\mathrm{xi}, \mathrm{xj})$ representing the direct dependencies between variables [12]. Assuming discrete variables, the importance of the relationship between variables is quantified by conditional probability distributions associated with each node. A special kind of BN named Dynamic Bayesian Networks (DBN) is proposed in a number of works [11, $19,20]$ to assess the reliability over time. DBN include a temporal dimension managed by time-indexed random variables, as presented in the following scheme in figure 2 .

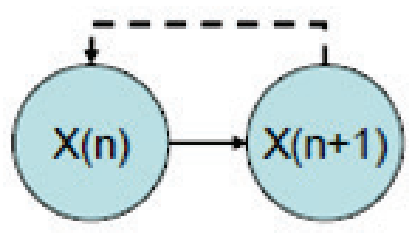

Fig. 2. Example of Dynamic Bayesian Networks

The table of passage from node $_{k}$ to node $_{k+1}$, resulting in the following matrix 1 of conditional probabilities [19].

$$
M\left(X_{k+1} \mid X_{k}\right)=\left[\begin{array}{cc}
\mathrm{P}\left(\{\mathrm{Up}\}^{\mathrm{k}+1} \mid\{\mathrm{Up}\}^{\mathrm{k}}\right) & \mathrm{P}\left(\{\text { Down }\}^{\mathrm{k}+1} \mid\{\mathrm{Up}\}^{\mathrm{k}}\right) \\
\mathrm{P}\left(\{\mathrm{Up}\}^{\mathrm{k}+1} \mid\{\text { Down }\}^{\mathrm{k}}\right) & \mathrm{P}\left(\{\text { Down }\}^{\mathrm{k}+1} \mid\{\text { Down }\}^{\mathrm{k}}\right)
\end{array}\right]
$$




$$
=\left[\begin{array}{cc}
1-\text { failure of } X & \text { failure of } X \\
0 & 1
\end{array}\right]=\left[\begin{array}{cc}
1-\lambda_{X} & \lambda_{X} \\
0 & 1
\end{array}\right]
$$

Such as :

$$
P\left(U p_{k+1} / U p_{k}\right)=1-\lambda_{x}
$$

Corresponds to the Conditional probability to non-failure.

$$
P\left(\text { Down }_{k+1} / U p_{k}\right)=\lambda_{x}
$$

Represents the Conditional failure probability of the component, which corresponds to the failure rate.

$$
P\left(U p_{k+1} / \text { Down }_{k}\right)=0
$$

Because it is impossible for the element to work again in $(t+1)$ knowing that it has failed at $t$ without repair.

$$
P\left(\text { Down }_{k+1} / \text { Down }_{k}\right)=1
$$

The element does not work again in $(t+1)$ knowing that it has failed at $(t)$ without repair.

\subsection{Modeling of Multi Domain Interaction}

In order to handle this interactive aspect, we proposed the representation of multi domain interactions as influence factors associated to stress acceleration laws, using a Dynamic Bayesian Network. Supposing that a component failure influences another component of a different nature, it will directly influence the failure rate of the second component. Hence, failure rates should be recalculated for the components influenced by this interaction. This computing have to be made by using the acceleration laws associated with stress, depending on the variation of the stress value.

Therefore, we can define multi-domain interaction as an influence factor between two components of different fields (mechanics, electronics, or software). Interactions are defined as a relationship cause and effect for a component failure mechanism, where the influence factor comes from other fields. Table 1 presents some examples of influence factors according to the components of mechatronic systems, issued from a dysfunctional qualitative modeling using FMEA method. 
Table 1

Example of multi domains interactions

\begin{tabular}{|c|c|c|c|}
\hline Domain & Electrical/ Thermal & Hydraulic/ Pneumatic & $\begin{array}{c}\text { Automatic/ } \\
\text { software }\end{array}$ \\
\hline Mechanical & $\begin{array}{c}\text { Shock. } \\
\text { Vibration } \\
\text { Overpressure }\end{array}$ & $\begin{array}{c}\text { Leakage ... } \\
\text { Water oil }\end{array}$ & Parameter error \\
\hline $\begin{array}{c}\text { Electrical/ } \\
\text { Thermal }\end{array}$ & & $\begin{array}{c}\text { Humidity } \\
\text { Temperature }\end{array}$ & $\begin{array}{c}\text { Over current } \\
\text { Over voltage }\end{array}$ \\
\hline $\begin{array}{c}\text { Hydraulic/ } \\
\text { Pneumatic }\end{array}$ & & $\begin{array}{c}\text { Over pressure } \\
\text { Parameter error }\end{array}$ \\
\hline
\end{tabular}

We propose to incorporate the stress law selected in the first stage, the failure rate associated with the affected component. According to the influence factor assigned to the multi-domain interaction, two cases should be considered: When the physical degradation of the component is known. First we propose to use the law associated to physical failure mechanism, such as Arrhenius for failure mode related to temperature. Eyring law for humidity [13] etc., if not the case, when the physical degradation is unknown. Cox's law can be used, based on statistical data as presented in the table 2 .

Table 2

Example of stress law depending to influence factor

\begin{tabular}{|c|c|c|}
\hline Data Interaction & Influence factor & Stress law \\
\hline \multirow{3}{*}{ Physical Data } & Temperature & Arrhenius Law \\
\cline { 2 - 3 } & Humidity & Peck Law \\
\cline { 2 - 3 } & Over pressure, Vibration & Power inverse Law \\
\cline { 2 - 3 } & Electro-migration & Black's Law \\
\hline Statistical Data & Multiple interactions & Cox Law \\
\hline
\end{tabular}

So, to represent the multi domain interaction, we propose to implement two points: 


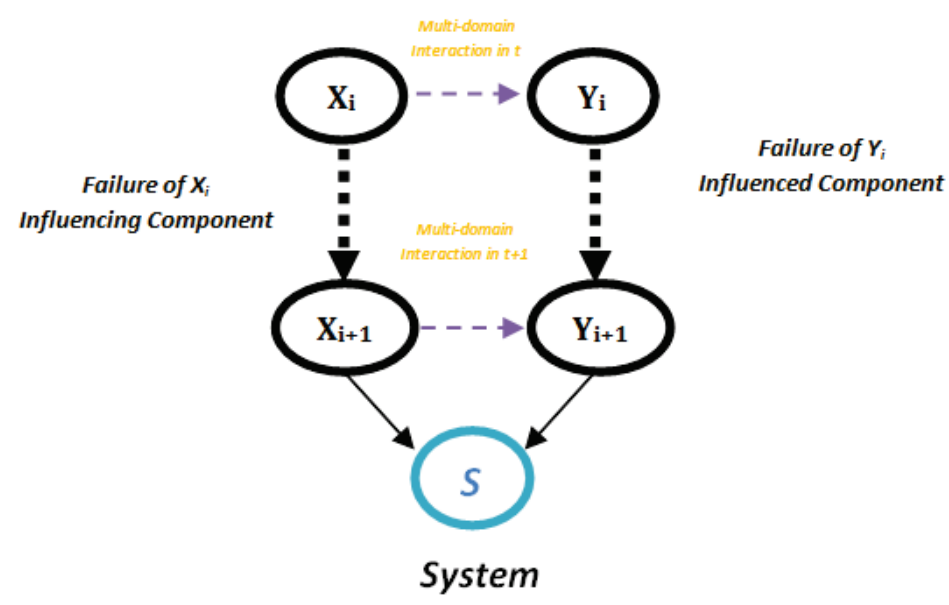

Fig. 3. Multi-domain Interaction representation

- Adding an arc between the "Y/X" (Influencing/ Influenced Component) nodes in BN model.

- Changing the conditional probability table of influenced component node (table 4).

$$
\boldsymbol{P}\left[\left(\mathrm{X}_{\mathrm{k}+1}=\mathrm{Down}\right) /\left(\mathrm{X}_{\boldsymbol{k}}=\mathrm{Up}\right) \cap\left(\mathrm{Y}_{\mathrm{k}+1}=\mathrm{Up}\right)\right]=\mathbf{1}-\boldsymbol{\lambda}_{\text {reference }}
$$

Interaction does not exist. The conditional probability is the same of equation 4.

$$
\boldsymbol{P}\left[\left(\mathrm{X}_{\mathrm{k}+1}=\mathrm{Down}\right) /\left(\mathrm{X}_{\boldsymbol{k}}=\mathrm{Up}\right) \cap\left(\mathrm{Y}_{\mathrm{k}+1}=\mathrm{Down}\right)\right]=\mathbf{1}-\boldsymbol{\lambda}_{\text {Interaction }}
$$

Represents probability of $\mathrm{X}$ failure, knowing that the $\mathrm{Y}$ is in degraded mode, which corresponds to the interaction failure rate.

\section{Table 3}

\section{CPT of $X_{t+1}$ node}

\begin{tabular}{|c|c|c|}
\hline$X_{t}$ & Up & Down \\
\hline Up & $1-\lambda_{\text {reference }}$ & $\lambda_{\text {reference }}$ \\
\hline Down & 0 & 1 \\
\hline
\end{tabular}


The " $\mathrm{X} / \mathrm{Y}$ " interaction is associated to the node $\mathrm{X}_{\mathrm{t}+1}$, and the proposed CPT for the interaction is presented in table 3.

Table 4

CPT of $Y_{t+1}$ node

\begin{tabular}{|c|c|c|c|}
\hline$Y_{t}$ & $X_{t}$ & $U p$ & Down \\
\hline \multirow{2}{*}{$U p$} & $U p$ & $1-\lambda_{\text {reference }}$ & $\lambda_{\text {reference }}$ \\
\cline { 2 - 4 } & Down & 0 & 1 \\
\hline \multirow{2}{*}{ Down } & $U p$ & $1-\lambda_{\text {Interaction }}$ & $\lambda_{\text {Interaction }}$ \\
\cline { 2 - 4 } & Down & 0 & 1 \\
\hline
\end{tabular}

\section{Application on Smart Actuator}

To illustrate the proposed method for the estimation of the predicted reliability of mechatronic system, we chose an application of PACK'AERO [9], the Smart Actuator. This system is a mechatronic system designed to carry out the unloading function of the wagons. The main issue is a multi-domain interaction "coil/bearing" as an interaction between the electric domain and mechanical domain. The application revealed some critical elements: Control and diagnostic card of the actuator, Hall sensor, coil and guide bearing. A series configuration was considered and the rest of the elements of the system are not taken into account. The following figure 4 .
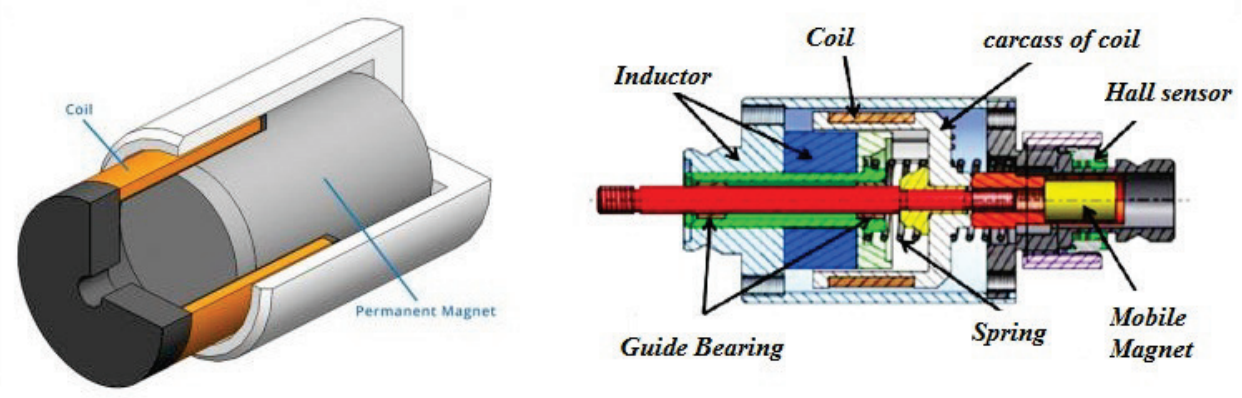

Fig. 4. Smart Actuator PACK'AERO 


\subsection{Quantitative modeling of Smart Actuator}

The qualitative modeling (functional and dysfunctional) has been described by G. Habchi [9]. Based on the failure rate of components given in table 5. The Assessment of system reliability without taking account any multi-domain interaction is presented in figure 5, based on DBN model presented in figure 6 .

Table 5

\section{Component failure rate}

\begin{tabular}{|c|c|}
\hline Component & Failure rate $(1 / \mathrm{h})$ \\
\hline Coil Electrical & $1.16 \mathrm{E}-06$ \\
\hline Hall sensor & $1.21 \mathrm{E}-07$ \\
\hline Control Card & $1.72 \mathrm{E}-07$ \\
\hline Guide Bearing & $\mathrm{MTTF}=0.81 \mathrm{E}+03$ \\
$\mathrm{~B}=1.5$
\end{tabular}
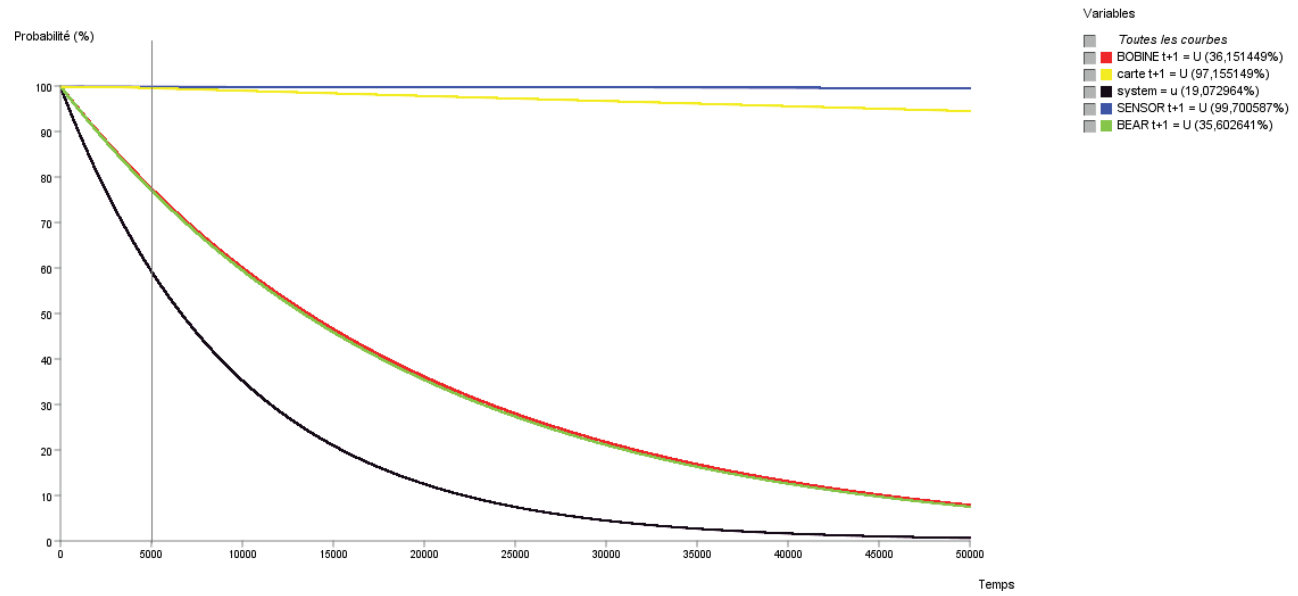

Fig. 5. Reliability of Actuator system without multi-domain interaction

\subsection{Modeling of multi-domain interaction "Coil/Bear"}

The multi-domain interaction is the interaction between "Coil/Bear" during the "hot phase" of the mission profile [9]. The problem comes from warming generated by bear in degradation state, this warming propagates and coil breaks down. We 
propose to consider this multi-domain interaction as an influence factor of Temperature, modeled by the Arrhenius law. Since we have a single interaction, applying the Cox model would not be appropriate. The temperature increase generated by the bearing will accelerate the failure of the coil; the failure rate of the influenced component (the coil) is calculated with the Arrhenius law according to table 2.

\subsubsection{Formulation of the Arrhenius Law}

Let's present the influence factor (temperature) associated to Arrhenius Law by considering the following model deterministically relating the life time of a component to its operating temperature [13]:

$$
v(T)=A_{0} \cdot e\left(-E a / K^{*} T\right)
$$

With:

- $v(\mathbf{t})$ : Component lifetime.

- $\mathbf{k}=8,6171 \times 10^{-5} \mathrm{eV} /{ }^{\circ} \mathrm{C}$ Boltzmann constant

- Ea: activation energy parameter characterizing the kinetics of degradation.

- $\mathbf{A}_{0}$ : constant associated with the component.

- $\mathbf{A}_{\mathrm{f}}$ : The acceleration factor between two different temperatures T and T'.

$$
A_{f}=T^{\prime} / T^{*} \exp \left[-E_{a} / K^{*}\left(1 / T-1 / T^{\prime}\right)\right]
$$

By approximation [13], we obtain the failure rate of the coil which is used in the following:

$$
\lambda\left(T, T_{0}, \lambda_{\text {reference }}\right) \cong \lambda_{\text {reference }} e\left(-T_{a} / T\right)
$$

With Ta: temperature of activation of component degradation.

For our application, by this approximation of the Arrhenius law, we obtain the failure rate of the coil in both cases:

- $\lambda$ coil-ref $=0.051 \mathrm{E}-3 \mathrm{~h}^{-1}$.

- $\lambda$ coil-Arrhenius $=0.17 \mathrm{E}-3 \mathrm{~h}^{-1}$ : with Coil-Bear Interaction .

The figure 6 shows the two Bayesian networks for the Smart actuator as a coherent system, one for each case (with/without multi-domain. The model was created using BayesiaLab software V.6. 


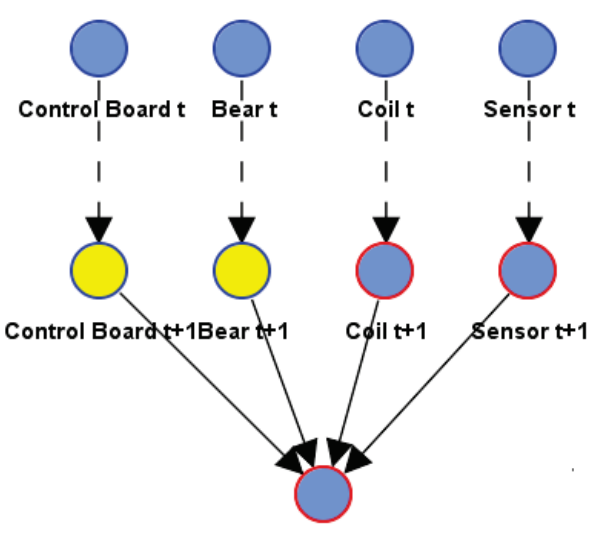

SYSTEM WITHOUT MULTI DOMAIN INTERACTION

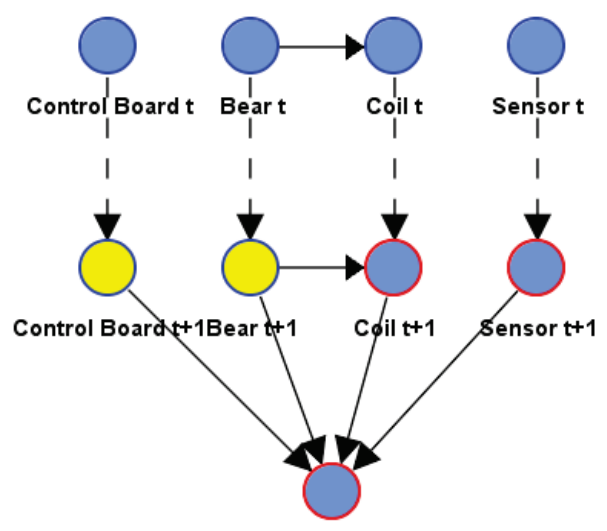

SYSTEM WITH MULTI DOMAIN INTERACTION

Fig. 6. Bayesian model reliability for actuator system with/without coil-bear interaction

Table 6

\section{CPT of Bear nodet +1}

\begin{tabular}{|c|c|c|c|}
\hline \hline Coil & Bear & Up & Down \\
\hline \multirow{2}{*}{ Up } & Up & $1-\lambda$ Coil & $\lambda_{\text {Coil }}$ \\
\cline { 2 - 4 } & Down & 0 & 1 \\
\hline \multirow{2}{*}{ Down } & UP & $1-\lambda_{\text {Arrhenius }}$ & $\lambda_{\text {Arrhenius }}$ \\
\cline { 2 - 4 } & Down & 0 & 1 \\
\hline
\end{tabular}

Table 5

CPT of Coil nodet +1

\begin{tabular}{|c|c|c|}
\hline Bear & Up & Down \\
\hline UP & $1-\lambda_{\text {Bear }}$ & $\lambda_{\text {Bear }}$ \\
\hline Down & 0 & 1 \\
\hline
\end{tabular}

The reliability curves for the actuator system and its four components (Coil, Sensor, Bear and Inductor) obtained by simulation with BayesiaLab software V.6 are represented in figure 7 and 8 .

Taking into account the Coil-Bear interaction (figure 7) clearly appears on the components of the coil and the bearing involved in the interaction: the reliability of these two components criticism is strongly weakened by interaction. 


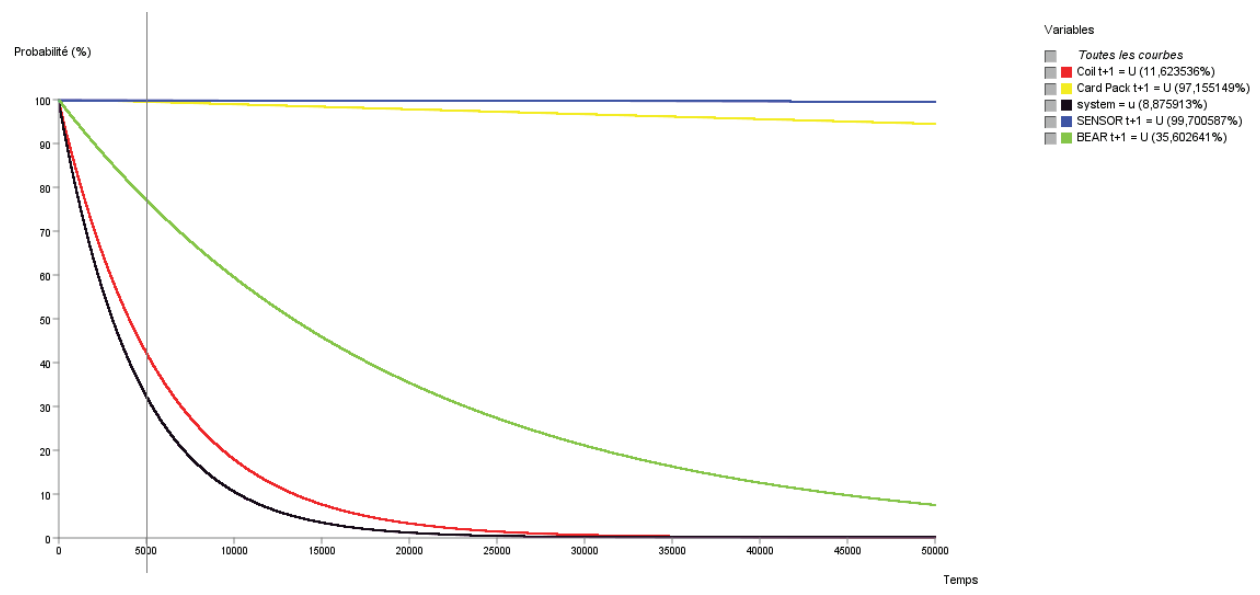

Fig. 7. Reliability of actuator system with Coil-Bear Interaction

From figure 7, the interaction between guide bearing and coil has a strong impact on reliability of coil. The coil is the critical component on reliability of smart actuator.

To analyze the impact of multi-domain interaction, we present the curves of reliability of system and coil (as the major component influenced by interaction) in figure 8 . The table 7 contains results at 5000 hours ( 7 months). 


\subsubsection{Comparison of results}

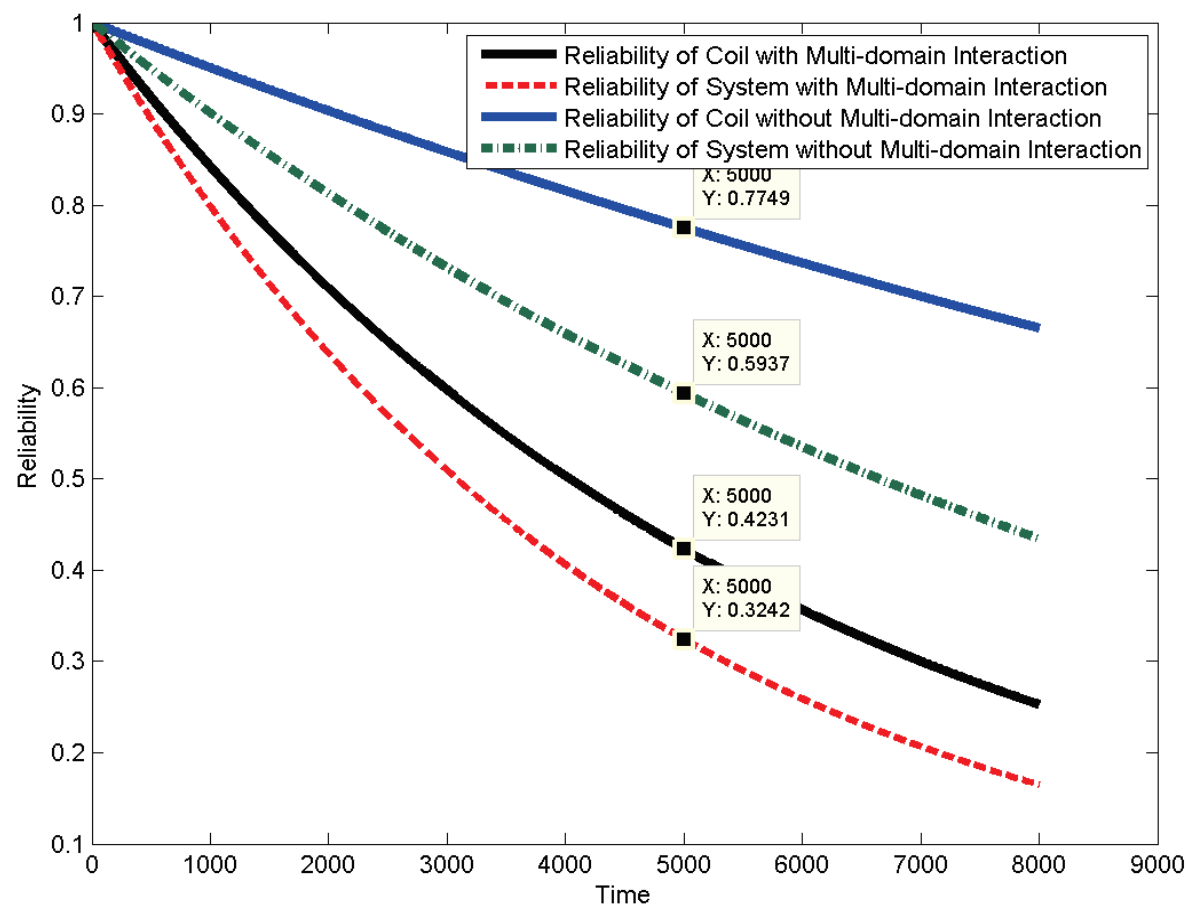

Fig. 8. Reliability of actuator system with/without Coil-Bear Interaction

Table 7

\section{Comparison of results}

\begin{tabular}{|l|c|c|}
\hline & Without M-Interaction & With M-interaction \\
\hline System Reliability $(\mathrm{t}=5000 \mathrm{~h})$ & 0.593 & 0.324 \\
\hline Coil Reliability $(\mathrm{t}=5000 \mathrm{~h})$ & 0.774 & 0.423 \\
\hline
\end{tabular}

Comparing the two cases (with/ without Coil-Bear interaction), the drop is clearly visible from 5000 hours to 10000 hours, we can notice that taking into account the interaction has a major influence on system reliability evaluation prediction. On this example, the two reliability prediction have a strong difference. It can be useful for mechatronics engineers to integrate the impact of multi-domain interaction in the future risk analysis. If test results are available, it will be possible to distinguish the two hypothesis (With or without interaction) to reduce model uncertainties. 


\section{Conclusion}

In this paper, we proposed a new methodology to model the reliability of mechatronic systems, considered as interactive dynamic systems, by using DBN for studying the interactive aspect. The multi-domain interaction was modeled as an influence factor associated to stress acceleration laws. To illustrate the interest of the proposed methodology, it was applied on the Smart Actuator. The interaction studied is the one between the electrical coil and the guide bearing, considered as an influence factor associated to an acceleration law. The same approach can be applied in the case of a mechatronic system with several multi-domain interactions, by using others stress acceleration laws, as for example Cox's law. The results obtained show the impact of multi-domain interaction on the reliability of the mechatronic systems.

Without knowledge on multi-domain interaction at reliability prediction phase, mechatronics engineers have to collect test data and to investigate which interaction has an impact. A perspective to provide test hypothesis taking into account epistemic uncertainties (model and parameter uncertainties) that allow reliability engineers to conclude on multi-domain interaction impact on system reliability.

\section{References}

1. Amrani N.B., Saintis L., Sarsri D., Barreau M.: Evaluating the predicted reliability of mechatronic systems: State of the art. Mechanical Engineering: An International Journal (MEIJ), 3(2) 2016.

2. Amrani N.B., Saintis L., Sarsri D., Barreau M.: Prise en compte des interactions multidomaines lors de l'évaluation de la fiabilité prévisionnelle des systèmes mécatroniques. Proc. Int. Lambda Mu 20, France, Saint-Malo 2016.

3. Barreau M., Todoskoff A., Morel A., Guerin F., Mihalache A.: Dependability assessment for mechatronic systems: electronic stability. 5th IFAC Symposium Fault Detection, Supervision and Safety, Safe process, USA, Washington 2003.

4. Belhadaoui H.: Conception sûre des systèmes mécatroniques intelligents pour des applications critiques. Automatique. PhD Thesis, Institut National Polytechnique, France, Lorraine 2011.

5. Bishop R.H., The mechatronic HANDBOOK. The publishing division of ISA The Instrumentation, Systems, and Automation Society, 2002.

6. Bobbio A., Portinale L., Minichino M., Ciancamerla E.: Improving the analysis of dependable systems by mapping fault trees into Bayesian networks. Reliability Engineering and System Safety, 71,3, 2001. 
7. Deleuze G., Quatrain R., Jouanet F., Talbourdet D., Lucet F.: A Method for the Assessment of Common Cause Failures of Digital I and C Hardware. The annual European Safety and Reliability Conference ESREL, Finland, Helsinki 2012.

8. Demri A., Guerin F., Bigaud D.: Mechatronic system reliability evaluation using Petri networks and phi 2 method. Proceeding Int. Conf. European Safety and Reliability Conference ESREL, Czech Republic, Prague 2009.

9. Habchi G., Barthod C.: An overall methodology for reliability prediction of mechatronic systems design with industrial application. Reliability Engineering and System Safety. Vol. 155(C), DOI: 10.1016/j.ress.2016.06.013.

10. Khalfaoui S., Guilhem E.E., Demmou H., Valette R.: A method for deriving critical scenarios in mechatronic systems. Proc. Int. Conf. Lambda mu 13 Europeen Conference on System Dependability and Safety, France, Lyon 2002.

11. Langsetha H., Portinaleb L.: Bayesian networks in reliability. Elsivier, Reliability Engineering System Safety, Vol. 92, Iss. 1, 2007.

12. Leger A., Weber P., Levrat E., Duval C., Farret R., Iung B.: Methodological developments for probabilistic risk analyses of socio technical systems. Proceedings of the institution of Mechanical Engineers, Part O: Journal of Risk and Reliability. 223(4), 313, 2009, DOI:10.1243/1748006XJRR230.

13. Meeker W.Q., Escobar L.A.: A statistical methods for reliability data. Wiley, Quality Productivity and Reliability, New York 1998.

14. Mihalache A., Guerin F., Barreau M., Todoskoff A., Bacivarov I.: Reliability building of mechatronic systems. Proc. Int. the IEEE 10th International Conference on Quality and Dependability, Romania, Sinaia 2006.

15. Moncelet G., Christensen S., Demmou H.: Analysing a mechatronic system with coloured Petri net. International Journal on Software Tools for Technology Transfer. Springer. 221998.

16. Saintis L., Hugues E., Bes C., Mongeau M.: Computing In-Service Aircraft reliability. International Journal of Reliability Quality and Safety Engineering, 16, 91, 2009.

17. Schoenig R., Aubry J., Cambois T., Hutinet T.: An aggregation method of Markov graphs for the reliability analysis of hybrid systems. Reliability Engineering and System Safety. 91, 2006.

18. Sharma R.K., Sharma P.: Qualitative and quantitative approaches to analyse reliability of a mechatronic system: A case. Journal of Industrial Engineering International, Springer, Heidelberg, Vol. 11, 2015, DOI 10.1007/s40092-015-0098-6.

19. Weber Ph., Joue L.: Reliability modeling with dynamic Bayesian networks. 5th IFAC Symposium on Fault Detection, Supervision and Safety of Technical Processes, USA, Washington 2003.

20. Wójcicki T.: Use of Bayesian networks and augmented reality to reliability testing of complex technical objects. Journal of KONBiN, Vol. 35, No. 1, 2015.

21. Ziegler Ch., Sûreté de fonctionnement d'architectures informatiques embarquées sur automobile. PhD Thesis, Institut National Polytechnique INPT, France, Toulouse 1996. 